\title{
Flow Rate Determination as a Function of Rainfall for the Ungauged Suhareka River
}

\author{
Laura Kusari', Lavdim Osmanaj ${ }^{*}$, Hana Shehu', Samir Bungu' \\ 1 Faculty of Civil Engineering, University of Pristina, Kosovo \\ * Corresponding author's e-mail: lavdim.osmanaj@uni-pr.edu
}

\begin{abstract}
For ungauged rivers, when there are no hydrological measurements and there is a lack of data on perennial flow rates, the latter one to be determined based on other hydrological data. The river Suhareka catchment represents a similar case. Since there is no data on Suhareka's flow rates, the authors of this study aimed for the flow rate determination based on rainfall measurements. From the available data on annual precipitation (monthly sums) provided by the Kosovo Hydrometeorological Institute for the Suhareka hydrometric station, the observed monthly rainfall data for 30 years were analysed. Those gaps were initially filled by connecting the hydrometric station in Suhareka with those of Prishtina, Prizren and Ferizaj, and as a result a fairly good fit was ensured. Moreover, the intensity-duration-frequency curves were formed using the expression of Sokolovsky, as a mathematical model of the dependence $I(T, P)$. For a transformation of rainfall into flow, the American method SCS was used. As a result, the equation for the Suhareka River basin was derived, which enabled the determination of maximum inflows, for different return periods. The results obtained through this paper, indicates that even for ungauged river basins the peak flows can be determined from available rainfall data.
\end{abstract}

Keywords: catchment area, regression coefficient, $\mathrm{CN}$ parameter, rainfall intensity, flow curves, rainfall floods.

\section{INTRODUCTION}

For the water management process, the data on river's flow rates it of utmost importance. Therefore, the river flow rate determination is a focus of every hydrological research. Runoff plots are very important means to monitor runoff and soil loss (Baoyan et al., 2017). Unfortunately, many catchments are ungauged, and thus there are limitations for flood calculation using rainfall-runoff models (Nam \& Shin, 2018). As stated, hydrological modeling is instrumental for both scientific application and for providing public services (Kolbjorn \& Alfredsen, 2020).

When there is a lack of data on the river flow rates and many parameters of catchment properties are missing, then another aproach must be considered. The measurement model states in the form of equations, the relationship between the measurements and the true value of interest (McMillan et al., 2018; Nearing et al., 2016). Due to the lack of flow rate measurements, the relationship between rainfall and flow can help solve this defficiency. The flow forecasting as investigated in this paper, can rely solely on using the available rainfall data.

The Suhareka muncipality is on the sothern part of Kosovo and is characterised with the continental climate with the Mediterenean impact. The Suhareka river, flowing through this region is a small river but with higher flow oscilations through out the year, meaning that the $Q_{\max } / Q_{\min }$ flow relation is quite high. The Suhareka River is also known as a dry river, but since 2015 it has been flooding the downstream areas about 3 times and damaging the agriculture and industrial activity in its vicinity. Therefore, the integrated flood management is a priority in this area and it requries the knowledge of the probabilistic flow duration curves. On the basis of the hydrologic data availibility, there are some methods that can be used in this regard. The rain intensity $(i)$ ore rain height $(H)$ dependence on duration time $(t k)$ and return period $(P)$, can be determined in 
a pluviograph station that has a long observation period, as a final product of statistical analyses of rain (KHMI, 1984.). As for the pluvial floods, these are dynamic processes influenced by rain intensity and its distribution, catchments area, river flow density, catchment land use, soil geologic structure, soil moisture content, soil infiltration rate, etc. For the rainfall-runoff relationship identification, the most common method is the SCS method that is based on the dynamic interaction between rain intensity, soil infiltration and surface runoff.

\section{FLOW TREND DYNAMICS AND DISTRIBUTION FUNCTIONS FOR EXTREME RAINFALL}

The available rainfall data, for a 30 year time period, have some data deficiency during this time; therefore, the statistical population parameters will be evaluated on the basis of the representative group. As it is known, the larger the representative group, the smaller will be the errors in the population parametrs estimation and vice versa. From the population, we have the yearly rainfall series for 80 years, including those years when the data are missing. The representative group chosen is a 30 year series (Table 1).

In order to evaluate the arithmetic mean of population, of the representative group, the

Table 1. Representative group of the rainfall population (KHMI, 1984)

\begin{tabular}{|c|c|c|c|}
\hline Year & $P_{\text {year }}(\mathrm{mm})$ & Year & $P_{\text {year }}(\mathrm{mm})$ \\
\hline $1954 / 55$ & 931 & $1970 / 71$ & 831 \\
\hline $1955 / 56$ & 778 & $1971 / 72$ & 616 \\
\hline $1956 / 57$ & 648 & $1972 / 73$ & 960 \\
\hline $1957 / 58$ & 786 & $1973 / 74$ & 782 \\
\hline $1958 / 59$ & 719 & $1974 / 75$ & 714 \\
\hline $1959 / 60$ & 745 & $1975 / 76$ & 709 \\
\hline $1960 / 61$ & 781 & $1976 / 77$ & 849 \\
\hline $1961 / 62$ & 760 & $1977 / 78$ & 999 \\
\hline $1962 / 63$ & 969 & $1978 / 79$ & 876 \\
\hline $1963 / 64$ & 933 & $1979 / 80$ & 804 \\
\hline $1964 / 65$ & 716 & $1980 / 81$ & 894 \\
\hline $1965 / 66$ & 818 & $1981 / 82$ & 712 \\
\hline $1966 / 67$ & 773 & $1982 / 83$ & 720 \\
\hline $1967 / 68$ & 669 & $1983 / 84$ & 823 \\
\hline $1968 / 69$ & 751 & $X m e s .=$ & 794.8333 \\
\hline $1969 / 70$ & 779 & $\sigma=$ & 97.16218 \\
\hline
\end{tabular}

standard deviation of the population (SDP) (Bektesh $B, 2005$ ) has to be found first, as follows:

$$
S D P=\sqrt{\sigma^{2} \times \frac{n}{n-1}}
$$

where: $\sigma$ - standard deviation of the representative group; $n$-number of cases in group.

On the basis of the equation (1) it can be said that:

$$
S D P=\sqrt{97.16218^{2}} \times \frac{30}{30-1}=98.82
$$

While standard deviation of the arithmetic mean (SDXavg) will be:

$$
S D X a v g=\frac{S D P}{\sqrt{n}}
$$

respectively,

$$
S D X a v g=\frac{98.82}{\sqrt{30}}=18.04
$$

The results enable the finding of the boundary interval of the arithmetic mean of the population. As per the obtained results, for the probability coefficients $95 \%$, the boundary interval is calculated as follows:

$$
\begin{gathered}
794.833 \pm(1.96 \times 18.04) \\
794.833-(1.96 \times 18.04)=759.47 \\
\text { and } \\
794.833+(1.96 \times 18.04)=830.19
\end{gathered}
$$

With the probability as high as $95 \%$, it was found out that the mean arithmetic of population is within the range $759.47 \mathrm{~mm}$ and $830.19 \mathrm{~mm}$.

Standard error of the standard deviation (SEoSD) (Bektesh, 2005) is:

$$
S E O S D=\frac{S D}{\sqrt{2 n}}
$$

and

$$
S E O S D=\frac{98.82}{\sqrt{2} \times 30}=\frac{98.82}{7.746}=12.75
$$

Boundary intervals for the $95 \%$ probability is as following:

$$
98.82 \pm(1.96 \times 12.75)
$$

$$
\begin{gathered}
98.82-(1.96 \times 12.75)=73.83 \\
\text { and } \\
98.82+(1.96 \times 12.75)=123.81
\end{gathered}
$$

In theory and scientific research, trends are calculated as is regression, with the following formula: 
Annual Rainfall Trend

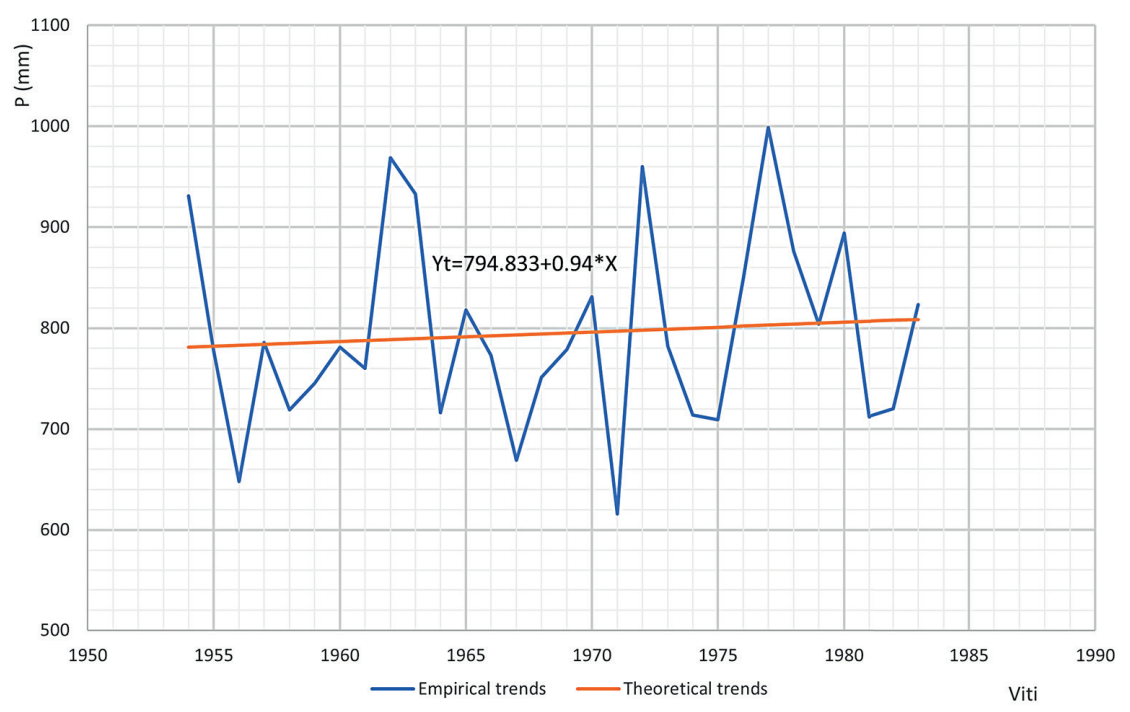

Figure 1. Annual series trend of the representative group

$$
y=a+b x
$$

Parameter (a) shows the mean value of the time series, while parameter $(b)$ shows the mean of the phenomena that is a study object, while $(x)$ are stanadard values given for each year (Figure 1).

$$
\begin{gathered}
a=\frac{\sum Y}{n} \\
b=\frac{\sum X Y}{\sum X^{2}}
\end{gathered}
$$

\section{Regression and correlation analyses}

In scientific research, the regression analyses is a very useful method of identifying the correlation between two or more variables or phenomena. The correlation between two variables is a bivariate correlation, while the correlation between three or more is known as a complex or multivariate correlation.

When ther is no linear function with the needed correlation coefficient of the $(y)$ as dependent variable, from a single (x) as an independend variable, then a possible correlation could be tested through multi linear regression. At double linear regression, the results can be stated as a line $y=b_{0}+b_{l} x$, where $\mathrm{b}_{0}$ is dependent from (z) (Maniak, 2010). Thus, a relationship $y$ $=y\left(x_{i} ; z_{i}\right)$ is obtained:

$$
y(x i ; z i)=b_{0}+b_{1 x}+b_{2 z}
$$

To determine the $b_{o}, b_{1}$ and $b_{2}$ coefficients, the sum of all small quadrates $\mathrm{S}$ should be kept in minimum:

$$
S=\sum_{i=1}^{N}\left[y i-y(x i ; z i]^{2}=\right.
$$

$$
=\sum_{i=1}^{N}\left[y i-\left(\begin{array}{c}
b o+b 1 \times x i+ \\
+b 2 \times z i
\end{array}\right)\right]^{2} \rightarrow \min
$$

By partaill derivation of this equation, through $b_{o}, b_{1}$ and $b_{2}$ coefficients, the $3 \times 3$ equation system is obtained:

$$
\begin{gathered}
\frac{\partial S}{\partial b o}=0 \rightarrow \sum_{i=1}^{N}\left(\begin{array}{c}
y i-b o- \\
-b 1 \times x i- \\
-b 2 \times z i
\end{array}\right)(-1)=0 \\
\frac{\partial S}{\partial b 1}=0 \rightarrow \sum_{i=1}^{N}\left(\begin{array}{c}
y i-b o- \\
-b 1 \times x i- \\
-b 2 \times z i
\end{array}\right)(-x i)=0 \\
\frac{\partial S}{\partial b 2}=0 \rightarrow \sum_{i=1}^{N}\left(\begin{array}{c}
y i-b o- \\
-b 1 \times x i- \\
-b 2 \times z i
\end{array}\right)(-z i)=0
\end{gathered}
$$

Knowing that and the relevant expressions for $\Delta \mathrm{xi}$ and $\Delta \mathrm{zi}$, following some transformations, the needed coefficients are the following:

$$
\begin{gathered}
b o=y m-b 1 \times x m-b 2 \times z m \\
b 1=\frac{-\sum \Delta x i \Delta y i \times \sum \Delta z i^{2}-}{\sum \Delta x i^{2} \times \sum \Delta z i i^{2}-\left(\sum \Delta x i \Delta z i\right)^{2}}
\end{gathered}
$$




$$
b 2=\frac{\sum \Delta y i \Delta z i \times \sum \Delta x i^{2}-}{\sum \Delta x i^{2} \times \sum \Delta x i \Delta i^{2}-\left(\sum \Delta x i \Delta z i\right)^{2}}
$$

The degree of determination is $B=r_{y x z}{ }^{2}$ and is defined as follows:

$$
\begin{gathered}
r_{y x z}^{2}=B=\frac{s_{y}^{2}(x i, z i)}{s_{y}^{2}}= \\
=\frac{\frac{\sum_{i=1}^{N}(y(x i, z i)-y m .)^{2}}{N-1}}{\frac{\sum_{i=1}^{N}(y i-y m .)^{2}}{N-1}}
\end{gathered}
$$

with:

$$
\begin{gathered}
s_{y}^{2}(x i, z i)=\frac{\sum_{i=1}^{N}\left(\begin{array}{c}
b 1 \times x i- \\
-b 2 \times z i
\end{array}\right)^{2}}{N-1}= \\
=\left[\begin{array}{c}
b 1 \times \sum \Delta x i \Delta y i+ \\
+b 2 \times \sum \Delta y i \Delta z i
\end{array}\right] /(N-1)
\end{gathered}
$$

Since $-1 \leq r \leq 1$, it implies that $0 \leq B \leq 1$.

In the considered case, the triple regression was obtained, connecting the hydrometric station of Suhareka (y) with those of Prizren ( $x$ ), Ferizaj $(z)$ and Prishtina $(t)$ (Maniak, 2010). From these analyses of variance, an important, but not sufficient correlation was obtained (Table 2, Figure 2).

According to this analysis, the regression equation will be:

$$
\begin{gathered}
y=455.2839+0.3215 x+ \\
+0.2394 z-0.1634 t
\end{gathered}
$$

The inadequacy of this relationship is also noticed by the high values of t-test and low ones of $F$-test as well as $P$-value which should be below the $5 \%$ probability level $(<0.05)$. However, the cause of the failure of a linear regression is usually the nonlinearity between the variables.

\section{Non linear regression and transformations}

The cause of failure of a linear regression is mainly nonlinearity between variables (Maniak, 2010; Husno, 2007). When using a nonlinear regression, the curve function is often unknown

\begin{tabular}{|c|c|c|c|c|c|c|c|c|}
\hline \multicolumn{9}{|c|}{ Summary output } \\
\hline \multicolumn{9}{|c|}{ Regression statistics } \\
\hline \multicolumn{5}{|c|}{ Multiple $R$} & \multicolumn{4}{|c|}{0.449555} \\
\hline \multicolumn{5}{|c|}{$R$ Square } & \multicolumn{4}{|c|}{0.2021} \\
\hline \multicolumn{5}{|c|}{ Adjusted $R$ Square } & \multicolumn{4}{|c|}{0.052494} \\
\hline \multicolumn{5}{|c|}{ Standard Error } & \multicolumn{4}{|c|}{91.1738} \\
\hline \multicolumn{5}{|c|}{ Observations } & \multicolumn{4}{|c|}{20} \\
\hline \multicolumn{9}{|c|}{ ANOVA } \\
\hline \multicolumn{2}{|c|}{ Parameters } & $d f$ & SS & & $M S$ & \multicolumn{2}{|l|}{$F$} & Significance $F$ \\
\hline \multicolumn{2}{|c|}{ Regression } & 3 & \multicolumn{2}{|c|}{33688.216} & 11229.41 & \multicolumn{2}{|c|}{1.35088} & 0.293297 \\
\hline \multicolumn{2}{|c|}{ Residual } & 16 & \multicolumn{2}{|c|}{133002.58} & 8312.661 & & & \\
\hline \multicolumn{2}{|l|}{ Total } & 19 & \multicolumn{2}{|c|}{166690.8} & & & & \\
\hline Parameters & Coefficients & $\begin{array}{l}\text { Standard } \\
\text { Error }\end{array}$ & $t$ Stat & $P$-value & Loëer 95\% & Upper 95\% & $\begin{array}{l}\text { Loëer } \\
95.0 \%\end{array}$ & $\begin{array}{l}\text { Upper } \\
95.0 \%\end{array}$ \\
\hline Intercept & 455.2839 & 177.71444 & 2.561884 & 0.020895 & 78.54608 & 832.0217 & 78.54608 & 832.0217 \\
\hline 690 & 0.321528 & 0.2162926 & 1.486541 & 0.156575 & -0.13699 & 0.780048 & -0.136992 & 0.780048 \\
\hline 757 & 0.239476 & 0.2685362 & 0.891782 & 0.385725 & -0.3298 & 0.808747 & -0.329796 & 0.808747 \\
\hline 695 & -0.16346 & 0.3472157 & -0.47076 & 0.644163 & -0.89952 & 0.572608 & -0.899521 & 0.572608 \\
\hline
\end{tabular}
(Karakuş, 2020). If the multiple nonlinear regressions are taken into account, then:

$$
y=a_{0} * x_{1}^{a 1} x_{2}^{a 2} x_{3}^{a 3} \ldots x_{n}^{a n}
$$

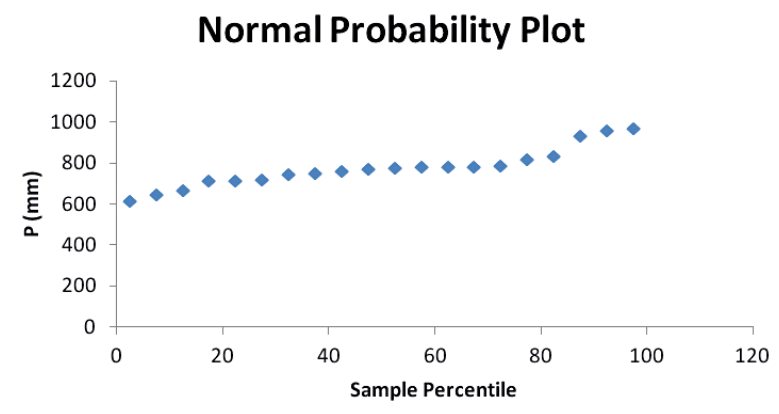

Figure 2. Normal probability plot

Table 2. Summary output of the multiple regression analyses 
which can be linearized using the following transformations:

$$
\begin{aligned}
& \log y=\log a_{0}+a_{1} \log x_{1}+ \\
& +a_{2} \log x_{2}+\cdots+a_{n} \log x_{n}
\end{aligned}
$$

On the basis of what was said above, similarly as in the case of linear regression, the Suhareka hydrometric station was connected with all three other stations. The nonlinear triple regression equation has the form $y=a_{0} * x_{1} a^{l} * x_{2} a^{2} * x_{3} a^{3}$ or $\log y=\log a_{0}+a_{1} * \log x_{1}+a_{2}^{*} \log x_{2}+a_{3} * \log x_{3}$, where after determining the coefficients $a_{0}, a_{1}, a_{2}$ and $\mathrm{a}_{3}$ the same takes the form:

$$
\begin{aligned}
& \log y=0.3057+0.384 * \log x_{1}+ \\
& +0.358 * \log x_{2}+0.172 * \log x_{3}
\end{aligned}
$$

or after anti-logarithm:

$$
y=2.02 * x_{1}^{0.384} * x_{2}^{0.358} * x_{3}^{0.172}
$$

The results of these calculations are shown in the Figure 3.

\section{Distribution functions for extreme rainfall}

At a first glance, it seems that between individual cases that produce mass phenomena, there is an irregularity and chaos, but when they are studied scientifically, it is seen that there are genuine regularity, principles and laws. These rules, principles and laws are best revealed by the law of large numbers of Laplace and Gauss.

The normal distribution is a symmetric twoparametric distribution with density function:

$$
\begin{gathered}
f(x)=\frac{1}{\sigma * \sqrt{2 \pi}} * \exp -\frac{1}{2} *\left[\frac{x-x m \cdot}{\sigma}\right]^{2} \\
-\infty<x<+\infty
\end{gathered}
$$

For standardization, take the standard variable $\mathrm{k}=\left(x-x_{m}\right) / \Sigma$ and for $x_{m}=0, \sigma=1$ we have:

$$
\begin{gathered}
f(k)=\frac{1}{\sqrt{2 \pi}} * \exp -\left[\frac{k^{2}}{2}\right] \approx 0.4 * e^{-\left(\frac{k^{2}}{2}\right),} \\
-\infty<k<+\infty
\end{gathered}
$$

The normal distribution function for calculating the stagnation probability is:

$$
\begin{gathered}
P(X \leq x)=\frac{1}{\sigma * \sqrt{2 \pi}} * \\
* \int_{-\infty}^{x} \exp -\frac{1}{2}\left[\frac{x-x m \cdot}{\sigma}\right]^{2} d x
\end{gathered}
$$

The normal distribution is represented by the surface under the density function, which can be formed by the area $x_{m} \pm k \sigma$ arranged symmetrically with the center. This area $\mathrm{x}_{\mathrm{m}} \pm \sigma$ contains $68.26 \%$ of all cases.

Normal distribution symmetry is used to represent the distribution as right in a suitable probability diagram. The straight line is easily determined by points, i.e the average $x_{m}$ in $P_{u}=$ $50 \%$ and the values $x_{m} \pm \sigma$, which are $84.13 \%$ and $15.87 \%$ (or $1 / 6$ of all values). With a linear division of the axes, the distribution function $\mathrm{P}(\mathrm{x})$

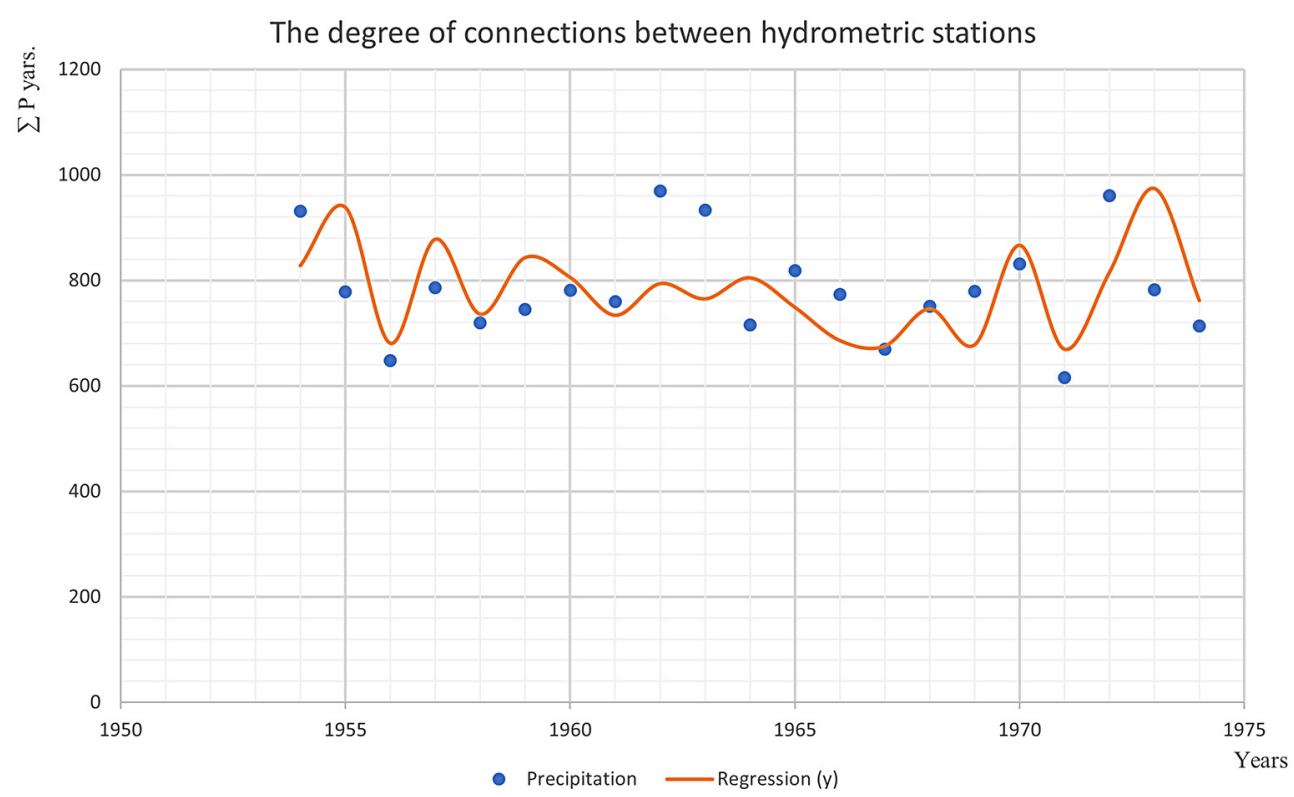

Figure 3. Degree of connections between hydrometric stations - triple nonlinear regression 
is an S-shaped curve. Taking an annual series of 38 -year rainfall and dividing it into classes with width $b=50 \mathrm{~mm}$, the statistical parameters of normal distribution are obtained:

$$
\begin{gathered}
x m=\frac{\sum_{i=1}^{N} n i * x i}{N}= \\
=\frac{29050}{38}=764.47 \mathrm{~mm} \\
\text { and } \\
\sigma=\sqrt{\frac{\sum n i *(x i-x m .)^{2}}{N-1}}= \\
=\sqrt{\frac{630789.47}{38-1}}=130.569 \mathrm{~mm}
\end{gathered}
$$

From here, $C v=\frac{\sigma}{x m}=\frac{130.569}{764.47}=0.1707$ while due to symmetry $C s=0$.

The normal distribution function takes the following values:

For $P_{u}=50 \% \rightarrow x=x_{m}=764.47 \mathrm{~mm}$; for $P_{u}$ $=84.13 \% \rightarrow x=x_{m}+\sigma=895 \mathrm{~mm}$; and for $P_{u}$ $=15.87 \% \rightarrow x=x_{m}-\sigma=633.9 \mathrm{~mm}$. The Table 3 presents these calculations for different probability factors (Figure 4).

Whereas, the density function takes these values: for $x=x_{m} \rightarrow f o=1 /(\sigma * \sqrt{2} \pi) * b * \exp -1 / 2 *(0)$ $=50 /(130.569 * \sqrt{ } 2 \pi)=0.1527$, similarly for the cases $x=x_{m} \pm \sigma ; x=x_{m} \pm 2 \sigma ; x=x_{m} \pm 3 \sigma$ are obtained
Table 3. Normal distribution values of the distribution function

\begin{tabular}{|c|c|c|c|}
\hline$P u=50 \%:$ & $x=x_{\text {mes }}=$ & 764.4736842 & $\mathrm{Mm}$ \\
\hline$P u=84.13 \%$ & $x=x_{\text {mes }}+s_{x}=$ & 895.0430687 & $\mathrm{Mm}$ \\
\hline$P u=15.87 \%$ & $x=x_{\text {mes }}-s_{x}=$ & 633.9042998 & $\mathrm{Mm}$ \\
\hline$P u=95 \%:$ & $x=x_{\text {mes }}+1.96 s_{x}=$ & 1020.389678 & $\mathrm{Mm}$ \\
\hline$P u=99 \%:$ & $x=x_{\text {mes }}+2.58 s_{x}=$ & 1101.342696 & $\mathrm{Mm}$ \\
\hline$P u=5 \%:$ & $x=x_{\text {mes }}-1.96 s_{x}=$ & 508.5576907 & $\mathrm{Mm}$ \\
\hline$P u=1 \%:$ & $x=x_{\text {mes }}-2.58 s_{x}=$ & 427.6046723 & $\mathrm{Mm}$ \\
\hline$\% P u$ & Gauss $(\mathrm{mm})$ & Galton $(\mathrm{mm})$ & \\
\hline 1 & 427.6046723 & 471.7654729 & \\
\hline 5 & 508.5576907 & 527.8134886 & \\
\hline 15.87 & 633.9042998 & 628.0165127 & \\
\hline 50 & 764.4736842 & 752.6742906 & \\
\hline 84.13 & 895.0430687 & 902.0759428 & \\
\hline 95 & 1020.389678 & 1073.331016 & \\
\hline 99 & 1101.342696 & 1200.847922 & \\
\hline
\end{tabular}

Table 4. Calculations

\begin{tabular}{|c|c|}
\hline \multicolumn{2}{|c|}{$x=x_{\text {mes }} \pm k^{*} \sigma k u ; k= \pm 1, \pm 2, \pm 3$} \\
\hline$x=x_{\text {mes. }}:$ & $f_{0}=0.152772476$ \\
\hline$x=x_{\text {mes }} \pm \sigma$ & $f_{1}=0.092661191$ \\
\hline$x=x_{\text {mes }} \pm 2 \sigma$ & $f_{2}=0.020675506$ \\
\hline$x=x_{\text {mes }} \pm 3 \sigma$ & $f_{3}=0.001697149$ \\
\hline
\end{tabular}

(Figure 5), in which case the calculations are formed in tabular form together with the Table 4 .

On the surface $\pm 3 \sigma$, which includes $99.73 \%$ of all cases $(0.9973 * 38=37.897)$, almost all

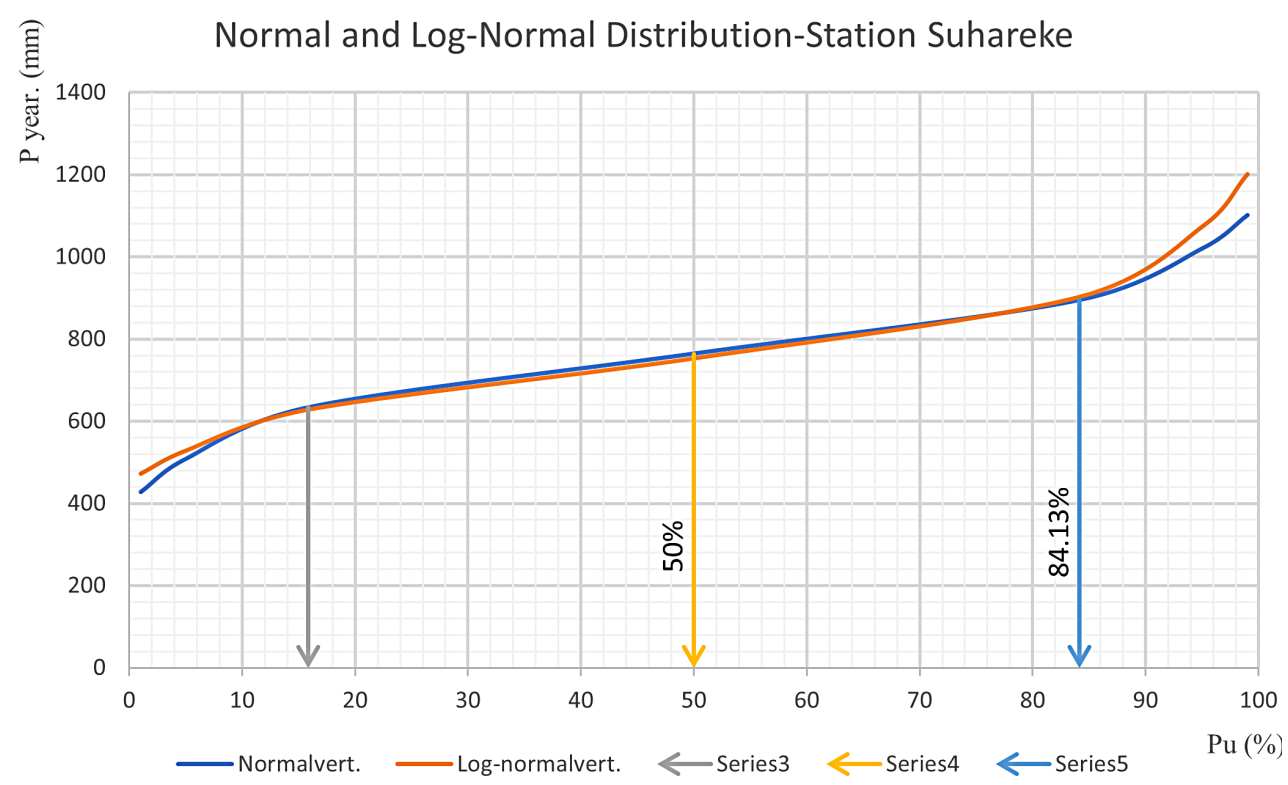

Figure 4. Normal and log-normal distribution - Station Suhareke 


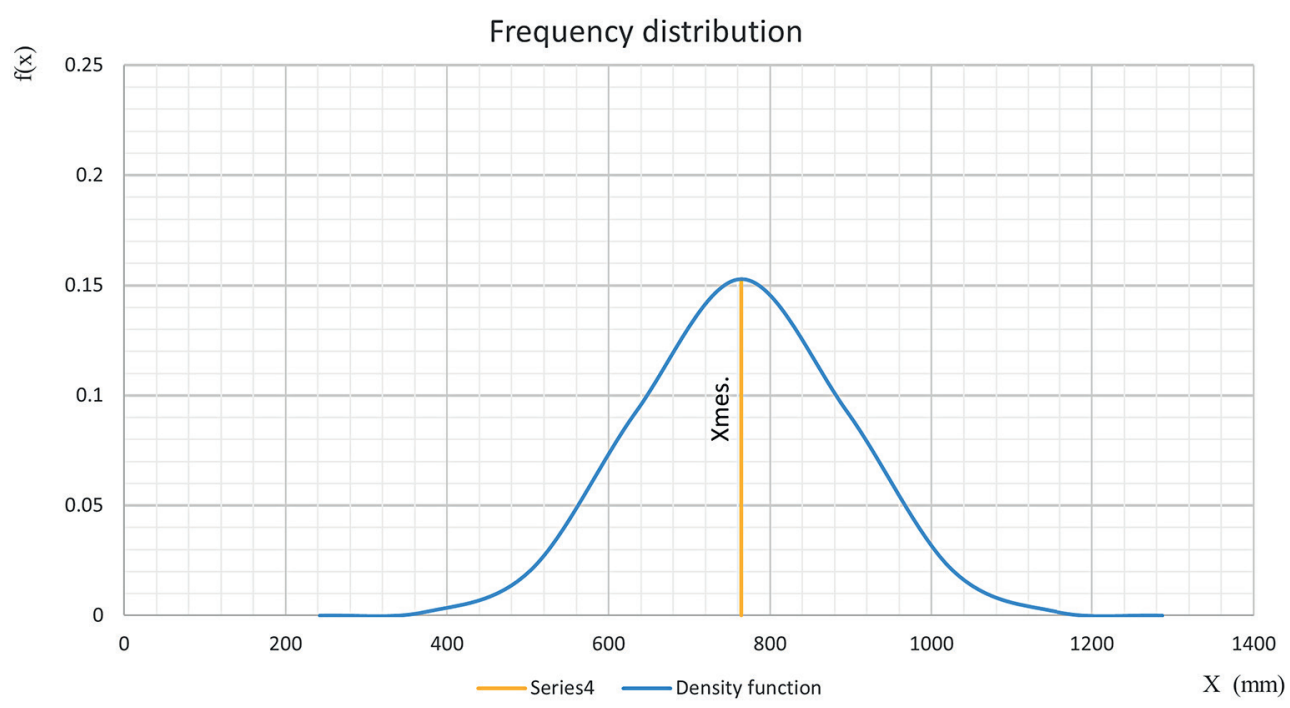

Figure 5. Normal distribution density function

cases of our group fall within the curve bounded by $x=x_{m} \pm 3 \sigma$.

Although only $0.26 \%$ of all values are out of bounds $x=x_{m} \pm 3 \sigma$, it is still a shortcoming of the normal distribution that its smallest value $-\infty$ is not physically meaningful. To obtain only the positive range (space) of cases, instead of $\mathrm{x}_{\mathrm{i}}$ we obtain $y_{i}=\log x_{i}$ or $y_{i}=\ln x_{i}$ (log-normal, Galton or Fechner distribution). In this case the function will be defined in the interval $(0, \infty)$.

\section{Autoregressive models for simulating monthly precipitation}

The time series models used are often based on the equation

$$
\begin{gathered}
x_{i}=\mu_{x}+\rho_{1} *\left(x_{i-1}-\mu_{x}\right) \\
+t_{i} * \sigma_{x} * \sqrt{\left(1-\rho_{1}^{2}\right)}
\end{gathered}
$$

known as the first-order equation of Markov models.

For the rainfall of a season or a year with average $\mu_{x}$ and autocorrelation coefficient $\rho$ with time shift 1 we have:

$$
q_{i}=\mu+\rho *\left(q_{i-1}-\mu\right)+e_{i}
$$

The recursion link for the generation of synthetic time series is the Fiering model. The application of the Fiering model to a normally distributed group with mean $\mu$, standard deviation $\sigma$ and autocorrelation coefficient $r_{i}$ is given by the recursion expression (Maniak, 2010; Mujumdar, 2019):

$$
\begin{aligned}
q_{i}=\mu & *\left(1-r_{1}\right)+r_{1} q_{i-1}+ \\
& +t_{i} \sigma \sqrt{\left(1-r_{1}^{2}\right)}
\end{aligned}
$$

To establish the recursion equation, the average monthly rainfall is initially calculated as:

$$
\mu_{j}=\frac{1}{N} * \sum_{k=1}^{N} x_{k, j}
$$

The variance of the individual time intervals (monthly) $\mathrm{t}$ will be:

$$
\begin{gathered}
\sigma_{j}^{2}=\frac{1}{N} \sum_{k=1}^{N} x_{k, j}- \\
-\frac{1}{N(N-1)}\left(\sum_{k=1}^{N} x_{k, j}\right)^{2}
\end{gathered}
$$

While the autocorrelation coefficient is calculated with the expression:

$$
r_{j}=\frac{\sum_{k=1}^{N} x_{k, j} x_{k, j-1}-N \mu_{j} \mu_{j-1}}{\sigma_{j} \sigma_{j-1}(N-1)}
$$

The general form of the equation suitable for use is:

$$
\begin{aligned}
q_{i, j}=\mu_{j} & +\frac{r_{j} \sigma_{j}}{\sigma_{j-1}} *\left(q_{i, j-1}-\mu_{j-1}\right)+ \\
& +t_{i, j} \sigma_{j} \sqrt{\left(1-r_{j}^{2}\right)}
\end{aligned}
$$

where: $q_{(i, j)}$ - the precipitation generated by string (i) in the i-th time interval, e.g for $t=1$ per month we have $j=1,2, \ldots, 12$; 
$\mu_{j}-$ monthly precipitation averages $(j)$ $(j \leq 12) ; \sigma_{j}-$ standard monthly deviation $(j)$; $r_{j}$ - the correlation coefficient between qj and $q j-1 ; t_{i}-$ random numbers normally distributed with $\mu=0$ and $\sigma=1$.

The ratio $\frac{r_{j} \sigma_{j}}{\sigma_{j-1}}=b j$ otherwise is known as the regression coefficient.

On the basis of what was said above, the 30year series of monthly rainfall were takend and the statistical parameters were set as in the Table 5 .

The model is based on equation (24), where 12 consecutive equations are described. The starting point is the average rainfall in October, 61.33 $\mathrm{mm}$. To generate synthetic time series, a sequence of randomly distributed random numbers were computed $z_{1}, z_{2}, \ldots$ These numbers $z_{\mathrm{i}}$ can be generated from a table of random numbers such as $-0.313,-0.951,0.590$ and so on.

However, according to the model, $z_{\mathrm{i}}$ numbers should be converted to random gamma distribution numbers according to the equation:

$$
\operatorname{tg}=\frac{2}{C_{t, j}}\left(1++\frac{C_{t, j} t_{i}}{6}-\frac{C_{t, j}^{2}}{36}\right)^{3}-\frac{2}{C_{t, j}}
$$

where $\mathrm{C}_{\mathrm{t}, \mathrm{j}}$ is the coefficient of asymmetry expressed by the equation

$$
C_{t, j}=\frac{C_{s j}-r_{j-1}{ }^{3} C_{s j-1}}{\sqrt{\left(1-r_{j}^{2}\right)^{3}}}
$$

where: $t_{i}$ - random numbers normally distributed $(0 ; 1), t_{g}$ - random gamma distribution numbers $\left(0 ; 1 ; C_{g}\right), C_{s j}-$ coefficient of asymmetry for months.

After converting these numbers, new numbers are obtained according to equation (25); where the 12 equations were then laid out for each month and the values were simulated:

First year:

$$
\begin{aligned}
q_{N}= & 86.7+0.0057 *\left(q_{i, o}-61.33\right)+ \\
& +t_{i} * 39.22 * \sqrt{\left(1-0.006^{2}\right)}
\end{aligned}
$$

Table 5. Statistical parameters of monthly precipitation in $(\mathrm{mm})$ for 30 -year series

\begin{tabular}{|c|c|c|c|c|c|}
\hline Month & $X_{\text {mes }}$ & $S_{j}$ & $C s$ & $r_{j}$ & $b_{j}$ \\
\hline N & 86.7 & 39.22187 & -0.00594 & 0.006158 & 0.005767 \\
\hline D & 80 & 39.41906 & 0.291129 & 0.13133 & 0.13199 \\
\hline J & 70.33333 & 46.03097 & 1.160096 & -0.17544 & -0.20487 \\
\hline F & 57 & 38.62017 & 0.937803 & 0.1177 & 0.098751 \\
\hline A & 65.5 & 46.08968 & 1.380183 & -0.24722 & -0.29504 \\
\hline M & 60.56667 & 25.39303 & 0.453322 & -0.08208 & -0.04522 \\
\hline M & 75.7 & 39.49784 & 0.768659 & -0.0487 & -0.07574 \\
\hline J & 65.86667 & 41.95789 & 1.671599 & -0.02247 & -0.02387 \\
\hline J & 62.63333 & 49.11737 & 2.635784 & -0.0126 & -0.01475 \\
\hline A & 45.63333 & 33.25501 & 0.658228 & -0.21308 & -0.14426 \\
\hline S & 63.56667 & 50.52939 & 1.741598 & 0.012554 & 0.019075 \\
\hline O & 61.33333 & 41.87776 & 0.600436 & -0.19055 & -0.15792 \\
\hline
\end{tabular}

\section{Coefficient of variation}

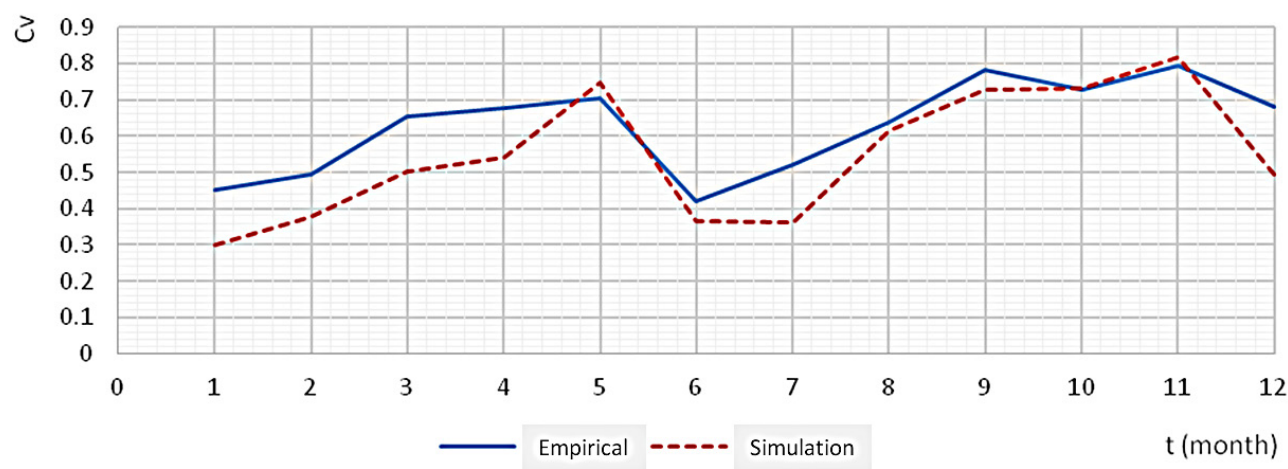

Figure 6. Model summary according to equation (24), for a 20-year simulated monthly rainfall hydrograph 


$$
\begin{gathered}
q_{D}=80+0.132 *\left(q_{i, N}-86.7\right)+ \\
\quad+t_{i} * 39.41 * \sqrt{\left(1-0.313^{2}\right)}
\end{gathered}
$$

Second year:

$$
\begin{gathered}
q_{N}=86.7+0.0057 *\left(q_{i-1, o}-61.33\right)+ \\
+t_{i} * 39.22 * \sqrt{\left(1-0.006^{2}\right)}
\end{gathered}
$$

The similarity of the empirical values with the simulated ones give a coefficient of variation which expresses the ratio of standard deviations and their arithmetic means (Figure 6).

\section{RESULTS AND DISCUSSION}

\section{Processing of IDF curves}

Assuming that the rainfall series follow the Pearson III distribution, and based on the data on the maximum daily rainfall for the Suhareka region, the probability distribution of heavy $24 \mathrm{~h}$ precipitation (according to the Pearson-III and log-Pearson-III distributions) for the combined series of maximum rainfall is determined.

Pearson-III distribution for a 30-year series of maximal daily precipitation has the following statistical parameters: $X_{m}=27.116 \mathrm{~mm} ; C_{v x}=0.338$; $C_{s x}=0.845$, while log-Pearson-III: $Y_{m}=1.409 ; C_{v y}$ $=0.104 ; C_{s y}=-0.129$.

As a mathematical model of the dependence $I(T, P)$ the following expression is taken (Babac, 2006).

$$
I(T, P)=\frac{I_{0}(P)}{(A * T+1)^{B}}
$$

where: $\mathrm{A}$ and $\mathrm{B}$ are dimensionless parameters, $I o(P)$ is the rainfall intensity limit, i.e. $\lim _{T \rightarrow 0} I(T, P)$. According to the Russian author Sokolovsy, this model was used for the territory of the European part of the former Soviet Union. If it is assumed that parameters $A$ and $B$ of equation (27) can be presented in the form of a map for the observed territory, then the intensity values of the boundary $I o(P)$ for a point can be determined through the corresponding values of the maximum daily rainfall $H d$ $(P)$. According to this model for rain duration $T=1440 \mathrm{~min}$. and probability $P$ :

$$
H(1440, P)=\frac{I_{0}(P)}{(1440 * A+1)^{B}} * 1440
$$

Relationship $H(1440, P)=a^{*} H_{d}(P)$ is quite logical, and that coefficient $(a)$ is close to unity because these are magnitudes determined by a series of annual maximum daily rainfall. Then, the following is derived from equation (28):

$$
\begin{gathered}
I(T, P)=\frac{a}{1440} * \\
*\left(\frac{1440 * A+1}{A * T+1}\right)^{B} * H_{d}(P)
\end{gathered}
$$

Using the last equation and the coefficients for Suhareka $(A=0.3 ; a=1.0 ; B=0.79)$ the following expression is obtained:

$$
\begin{gathered}
I(T, P)=\frac{1}{1440} * \\
\left(\frac{1440 * 0.3+1}{0.3 * T+1}\right)^{0.79} * H_{d}(P)
\end{gathered}
$$

It is worth noting that the parameter $A$ in the model in most cases is constant, while $B$ is the

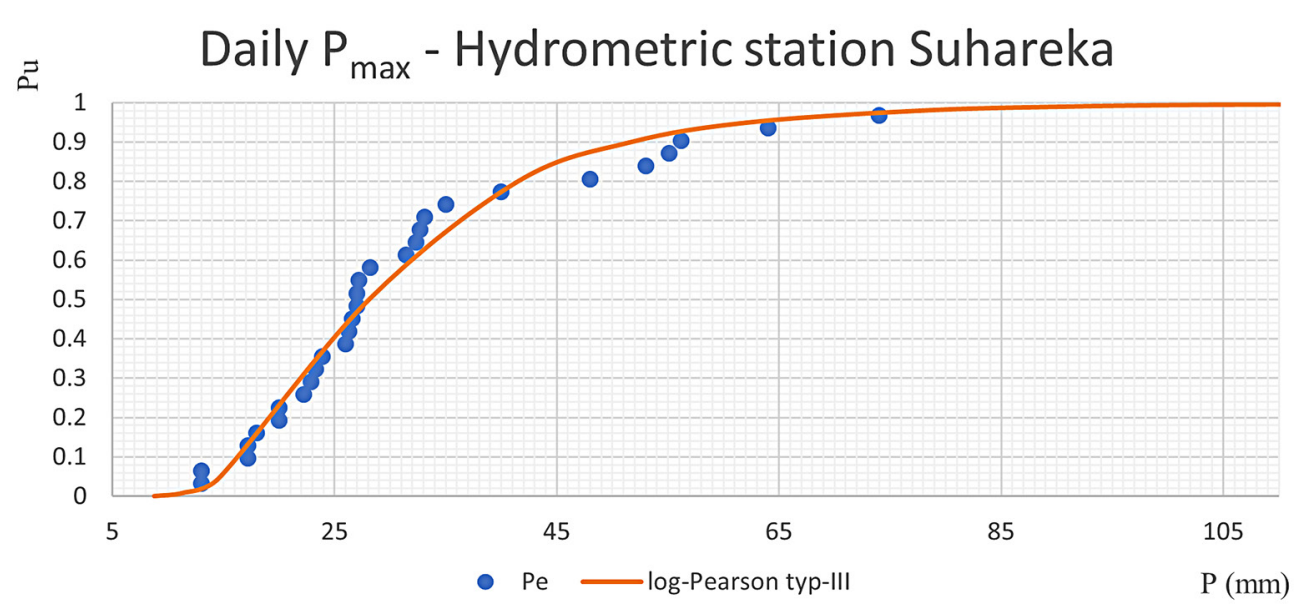

Figure 7. Probability of $24 \mathrm{~h}$ heavy rain distribution according to Pearson type-III 


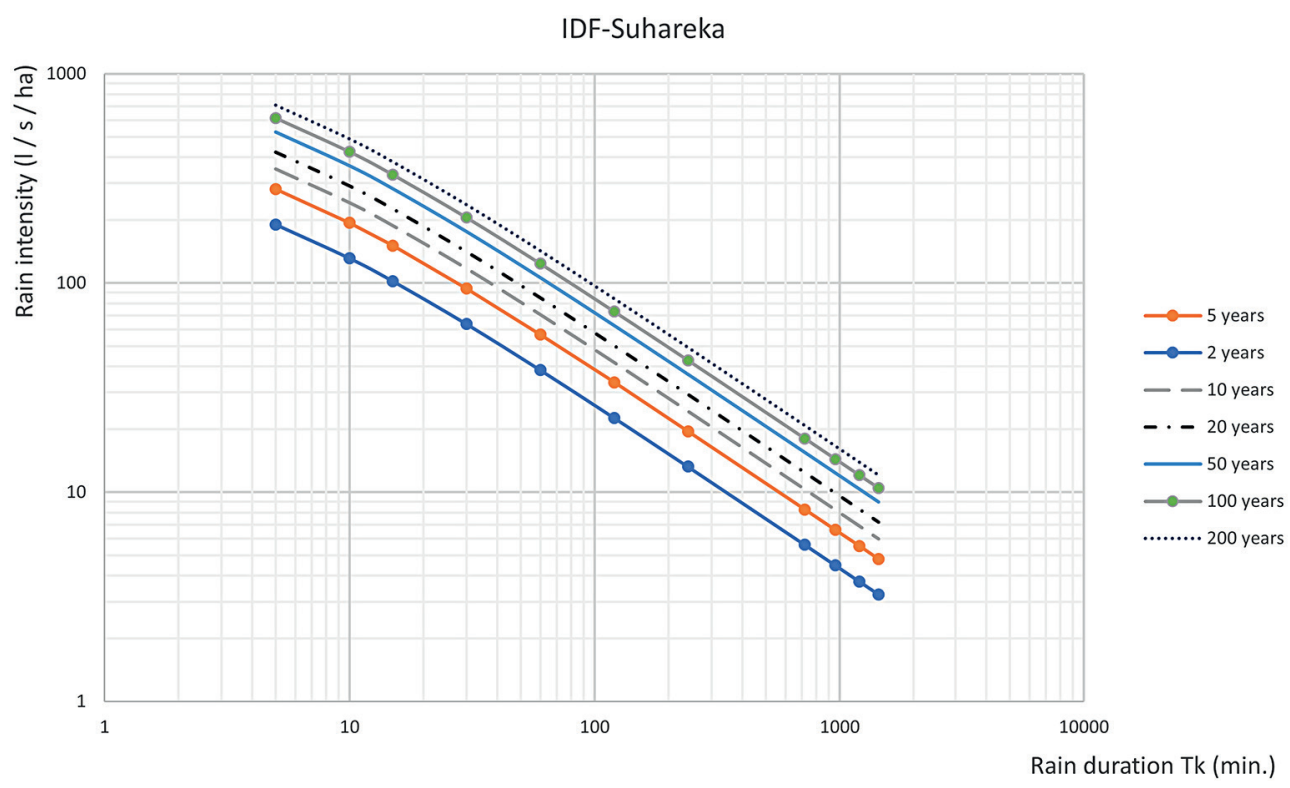

Figure 8. Precipitation intensity curves for different return periods

'coefficient of reduction of rainfall intensity over time' or as it is otherwise known the 'continental coefficient' which seems more acceptable because it has a physical interpretation.

According to the Pearson type-III distribution (Figure 7), the maximum daily rainfall heights for different return periods are calculated according to the expression $x_{T}=x_{m}+\sigma * k\left(C_{S x} ; T\right)$, where $\mathrm{k}$ - represents the frequency factor.

To assess the suitability of the theoretical distribution with the empirical one, statistical testing was performed according to the test $\chi_{2}$. The same resulted in the value $\mathrm{c} 2=2.64<c$ $=7.81$, which means that the hypothesis is accepted below the 1- $\alpha=5 \%$ probability level or statistical certainty is $95 \%$.

By substituting the rainfall heights for the respective return periods in eq. (30), rain intensities are found (Figure 8).

\section{Flow curves}

Since no flow measurements have been performed in the Suhareka region, then it is necessary for high waters to be indirectly determined by the transformation of rainfall into flow. For this purpose, the American SCS method is used, which uses the following characteristics of the basin: the length of the flow $(L)$, the length to the center of gravity of the river basin $(L c)$, the slope of the flow $\left(i_{u r}\right)$ and the surface of the river basin $(F)$.
Numerous analyses have shown that in the triangular-shaped synthetic hydrograph, the relationship between rain duration $(t)$ and delay time $\left(t_{p}\right)$ is linear. The latency time of the basin is defined by the expression:

$$
t_{p}=T_{0}+a * t_{k}
$$

where: $a$ - represents the regression coefficient which is a function of the surface $a=f(F)$, while $T_{0}$ depends on the topographic characteristics of the basin and is determined by the empirical expression:

$$
T_{o}=0.4 * L^{0.63} *\left(\frac{L * L_{c}}{\sqrt{i_{u r}}}\right)^{0.086}
$$

By recognizing precipitation with different durations and different return periods the effective precipitation can be determined according to the SCS method:

$$
P_{e}=\frac{(P-0.2 * d)^{2}}{P+0.8 * d},[\mathrm{~mm}]
$$

where: $d$ - soil moisture deficit, which is determined by the formula:

$$
d=\left(\frac{1000}{C N}-10\right) * 25.4,[\mathrm{~mm}]
$$

Whereas, the $\mathrm{CN}$ number expresses the characteristics of the soil in the catchment, which in the considered case is more complicated, since there are two groups of soils ( $B$ and $C$ ) with 
different composition: group B with about $40 \%$, and group $C$ with $60 \%$ participation. Thus, it turns out that the number $C N \cong 73$,

while $d=\left(\frac{1000}{73}-10\right) * 25.4=93.945 \mathrm{~mm}$.

Precipitation from IDF curves, due to the climatic effect and non-uniform distribution of precipitation is increased by $8 \%$, and the effective precipitation is determined according to equation (33).

For the Suhareka river basin the following characteristics can be used: $L=15 \mathrm{~km} ; L c=7.5$ $\mathrm{km} ; i_{u r} \cong 5 \%$ and $F=80.2 \mathrm{~km}^{2}$, of which according to equation (32) and (31) results: $T_{O}=3.761 \mathrm{~h}$ dhe $t_{p}=3.761+a * t_{k}$. For $F=80.2 \mathrm{~km}^{2}$ the regression coefficient is $a=0.44$. The setting time of the synthetic hydrograph is defined as: $T_{p}=t_{k} / 2+$ $+t_{p}=T_{o}+0.94 * t_{k}=3.761+0.94 * t_{k}$.
Due to the small surface area of the basin, it can be assumed that in the synthetic hydrograph it is $\operatorname{Tp}=\operatorname{Tr}$ (rise time $=$ fall time). Eventually, by condition:

$$
P_{e} * F=\frac{1}{2} * Q_{\max .} *\left(T_{p}+T_{r}\right)
$$

Derives,

$$
Q_{\max }=\frac{P_{e} * F}{T_{p}}
$$

By adjusting the units in the last equation, the maximum inflows for different return periods are obtained, which are presented in the Figure 9.

Finally, the dependence of the flow factor (X) of the area for different durations (h) and different return periods (years) is given. In this case, the effective rainfall is expressed according to the formula:

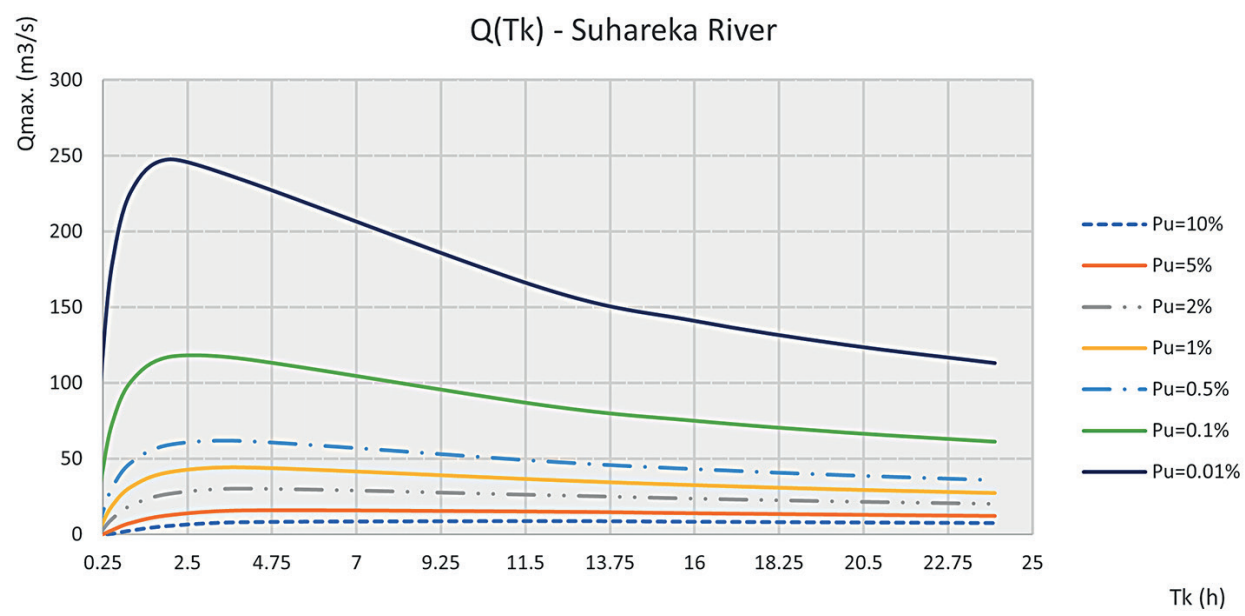

Figure 9. Maximum flows for different probabilities

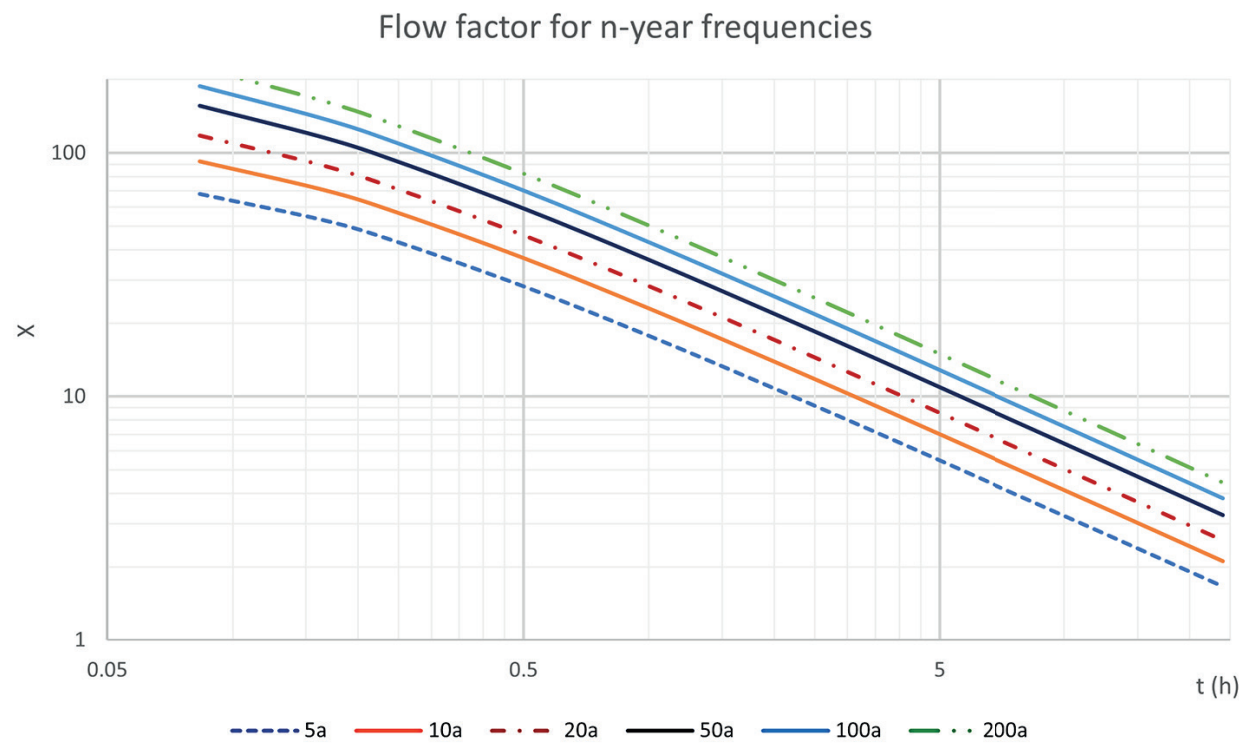

Figure 10. Flow factor for different return periods 


$$
P_{e}=\frac{\left(P-\frac{200}{C N}+2\right)^{2}}{P+\frac{800}{C N}-8}
$$

where: $P$ - precipitation for different return periods and $C N=73$.

The flow factor is determined according to the expression (Ven, 1962):

$$
X=\frac{P_{e}}{t}
$$

where: $t$ - time in hours (h).

\section{CONCLUSIONS}

The aim of this research was to estimate the flow for ungauged Suhareka River, based on the rainfall data available. In the considered case, the triple regression was obtained, connecting the hydrometric station of Suhareka (y) with those of Prizren $(x)$, Ferizaj $(z)$ and Prishtina $(t)$. From these analyses of variance an important, but not sufficient correlation was obtained. The inadequacy of this relationship is noticed by the high values of t-test and low ones of $F$-test as well as $P$-value. However, the cause of the insufficient correlationn is the nonlinearity between the variables, so after using transformation the Suhareka hydrometric station was connected with three other stations, using non linear triple regression analyses. The correlation coefficient in this case is higher than that of linear regression. Thus, $r_{\mathrm{yx} 1 \times 2 \times 3} \cong 0.62$, which represents a very important correlation of these stations.

The next step was the calculation of the distribution functions for extreme rainfall, with the use of Laplace and Gaussian law of large numbers. For a series of 30 years monthly rainfall data for the Hydrometric station in Suhareke, the Normal and Log Normal Distribution as well as Normal Distribution density function were calculated. Assuming that the rainfall series follow the Pearson III distribution, and based on the data on the maximum daily rainfall for the Suhareka region, the probability distribution of heavy $24 \mathrm{~h}$ precipitation (according to the Pearson-III and log-Pearson-III distributions) for the combined series of maximum rainfall is determined.

According to the Pearson type-III distribution, the heights maximum daily rainfall heights for different return periods, in Hydrometric Station Suhareks, are calculated.

Statistical testing was performed (according to the test $\chi_{2}$ to assess the suitability of the theoretical distribution with the empirical one. The results showed the acceptance of the hypothesis below the $1-a=5 \%$ probability level or with statistical certainty about $95 \%$.

Aa a result, the Precipitation intensity curves were given for different return periods. Since no flow measurements have been performed in the Suhareka region, the SCS method was used, by which the high waters were indirectly determined by the transformation of rainfall into flow. The equation for the Suhareka Basin charcteristics is derived $\frac{P_{e} * F}{T_{p}}$ for this purpose and the maximum inflows for different return periods were obtained.

The results obtained through this paper, indicates that even for ungauged river basins the peak flows can be determined from the available rainfall data. This will be of great help to the water engineers that are facing many data deficiencies while managing water resources.

\section{REFERENCES}

1. Baoyan L., Wang D., Fu S., Cao W. 2017. Estimation of peak flow rates for small drainage areas. Water Resources Management, 1635-1647.

2. Kolbjorn E., Alfredsen K. 2020. Hydrology and water resources management in a changing world. Hydrology Research, 143-145.

3. McMillan H., Westerberg I.K., Krueger T. 2018. Hydrological data uncertainty and its implications. Wiley Interdisciplinary Reviews Water. https://doi. org/10.3390/w10111669

4. Nam K.W., Shin M.J. 2018. Estimation of peak flow in ungauged catchments using relationship between runoff coefficient and curve number. Water.

5. Nearing G.S., Gupta H.V., Clark M.P., Tian Y., Harrison K.W., Weijs S.V. 2016. A philosophical basis for hydrological uncertainty. Hydrological Sciences Journal, 1666-1678.

6. Maniak U. 2010. Hydrologie und Wasserwirtschaft'; Eine einführung für Ingenieure, 6. neu bearbeitete Auflage. TU Braunschweig.

7. Ven T.C. 1962. Hydrologic determination of waterway areas for the design of drainage structures in small drainage basins. University of Illinois at Urbana-Champaign.

8. Husno H. 2007. Inẑenjerska Hidrologija. Sarajevo.

9. Babac P. 2006. Osnovi Hidrotehnike u šumarstvu primeri iz teorije i prakse. Beograd.

10. KHMI. 1984. Hydromeorological yearbooks of Kosovo 1954-1983.

11. Bektesh B. 2005. Statistika elementare Prishtinë.

12. Karakuş C. 2020. Istatistiksel analiz, olasılık ve rassal değişkenler. 